\title{
ORGAN SPARING TREATMENT FOR LOW RISK PENILE CANCER
}

MOHAMMAD GOLAM MOWLA CHOWDHURY, ISTEAQ AHMED SHAMEEM, MD. SAJID HASAN

Department of Urology, Bangabandhu Sheikh Mujib Medical University, Shabagh, Dhaka.

\begin{abstract}
Objective: The objective of this article is to provide an overview of the current concepts of organ-preserving procedures for penile cancer, and describe some of their indications, results and associated complications.

Methods: An extensive search of review articles of the Pubmed literature was performed to find articles discussing only organ sparing reconstructive surgery which have contributed significantly to change traditional, frequently mutilating treatments, to develop less disfiguring surgery, and to improve patients' quality of life over the last two decades.

Results: A large number of articles were included in this study in which a major contribution to the change in the treatment was thought to have occurred and was documented as beneficial. Some articles reported novel techniques of less-mutilating surgery involving different forms of glans reconstruction with the use of flaps or grafts. The issue of safe surgical margins was also addressed.

Conclusion: In highly selected cases of penile carcinoma, organ preserving techniques allowing phallus preservation has reduced the negative impact on functional and cosmetic outcomes of amputation without sacrificing oncological objectives based on stage, grade, and location of the tumour. Until more prospective studies are available and strong evidence is documented, organ preservation should be offered with caution.
\end{abstract}

Keywords: Organ sparing surgery, Penile Cancer, Low risk disease, Mohs Micrographic Surgery, Glans reconstruction.

Bangladesh J. Urol. 2015; 18(1): 33-39

\section{Introduction:}

Penile cancer is a rare tumor with specific geographical distribution of its incidence. Though it is uncommon in the Western world like Europe and USA, the incidence varies from 0.3 to $1 / 100000$ males. The highest incidence of $1 \%$ before the age of 70 years is seen in parts of Uganda, compared with the lowest cumulative rate of 300-times less amongst Israeli Jews [1,2]. While high incidence rates that account for up to $10-20 \%$ can be observed in some developing continents, like Asia, Africa and South America [3-5] In Brazil, 8.3 cases are diagnosed per 100,000 people [6]. This different worldwide

Correspondences: Mohammad Golam Mowla Chowdhury, Department of Urology, Bangabandhu Sheikh Mujib Medical University, Shabagh, Dhaka. E-mail: uromowla@hotmail.com distribution varies with age, personal hygiene and circumcision.

Historically, the majority (90\%) are primary carcinoma. Squamous cell carcinoma (SSC) is the predominant histological type, accounting for $95 \%$ of penile cancer cases and most men present with penile cancer in their $60 s$ [7]. Some risk factors associated with the development of the disease include phimosis, chronic inflammatory conditions such as balanopostitis, smoking and human papillomavirus infection [8].

The management of penile carcinoma, particularly its invasive form, has changed little over the decades. Available treatments include surgical amputation and penis-preserving treatments, either surgical 
(circumcision, laser ablation, Mohs micrographic surgery, glansectomy associated with various forms of reconstruction) or nonsurgical (radiotherapy, immunotherapy, chemotherapy). Surgical amputation is the oldest of all modalities [9]. It has resulted in local control rates greater than $90 \%$ of the primary tumor and, therefore, remains the oncological "gold standard" for all stages [10-12]. Although the radical surgical approach provides excellent local control, it is often mutilating and is associated with urinary and sexual dysfunction as well as dramatic psychological morbidity [13]. These urinary and psychosexual negative factors have led to a significant change in the treatment approach to the primary penile lesion and to the development of several surgical organ-preserving techniques. Nowadays, the definitive treatment of penile carcinoma is stagedependent, with the penile-preserving options especially reserved for low-grade and low-stage tumors without oncological compromise. These aim of organ preservative techniques is to remove as little of the functional anatomy as possible, without compromising local oncological radicality [14]. However, data from retrospective studies suggest a statistically higher local recurrence rate following penis-preserving treatments compared with radical surgery. Most recurrences are surgically salvageable and overall mortality is comparable to primary amputation [15]. The objective of this article is to give an overview of the current status and the role of this organ preserving surgical options for penile carcinoma and state their limitations.

\section{Selection of patients for organ-sparing treatment}

When an organ-sparing treatment is contemplated, accurate tumor staging is essential in order to aid preoperative planning. On oncological point of view it is generally accepted low grade and low stage penile carcinomas associated with favourable histology (stages Tis, Ta, T1; grades 1 and 2) are at low risk for local progression and/or distant metastatic spread (Table 1). These patients are also the best candidates for penile preserving treatment options [2]. Palpation of the primary tumor and the inguinal nodes has been the traditional approach for assessment of local invasion of the corpora and skin, and the evaluation of inguinal nodal metastases. This approach can often be inaccurate, however MRI is the most accurate imaging modality for the assessment of primary penile cancers. It depicts the penile anatomy in detail, including the relationship of the tumor to the surrounding structures. Penile cancer is usually present as solitary, ill-defined infiltrating tumors that are hypointense on both T1- and T2-weighted MR images.
In addition, the recently introduced technique known as lymphotrophic nanoparticle-enhanced MRI can help to identify metastatic lymph node disease [16]. Recently, however, some series have suggested that these indications can be expanded in order to include $\mathrm{T} 2$ and even some distal T3 tumors as well as recurrences after radiotherapy [17]. Nonetheless, until more rigorous scientific evidence is available, organ-preserving strategies should be reserved to well-selected patients with limited low-grade, low-stage disease [18, 19]. A traditional $2 \mathrm{~cm}$ excision margin has been challenged as unnecessary for patients undergoing partial penectomy for squamous cell carcinoma. Conservative techniques involving free surgical margins of only less than $10 \mathrm{~mm}$ appear to offer excellent oncological control $[20,21]$.

Table-I

TNM clinical and pathological classification of penile cancer 2009 (EUA guideline 2014)

\section{Clinical classification}

$T$ - Primary Tumour

TX Primary tumour cannot be assessed

TO No evidence of primary tumour

Tis Carcinoma in situ

Ta Non-invasive carcinoma

T1 Tumour invades subepithelial connective tissue

T1a Tumour invades subepithelial connective tissue without lymphovascular invasion

and is not poorly differentiated or undifferentiated (T1G1-2)

T1b Tumour invades subepithelial connective tissue with lymphovascular invasion or is

Poorly differentiated or undifferentiated (T1G3-4)

T2 Tumour invades corpus spongiosum and/or corpora cavernosa

T3 Tumour invades urethra

T4 Tumour invades other adjacent structures

\section{$\mathrm{N}$ - Regional Lymph Nodes}

NX Regional lymph nodes cannot be assessed

NO No palpable or visibly enlarged inguinal lymph node

N1 Palpable mobile unilateral inguinal lymph node

N2 Palpable mobile multiple unilateral or bilateral inguinal lymph nodes

N3 Fixed inguinal nodal mass or pelvic lymphadenopathy, unilateral or bilateral

M - Distant Metastasis

MO No distant metastasis

M1 Distant metastasis 
Table-I (Contd.)

\section{Pathological classification}

The $\mathrm{pT}$ categories correspond to the clinical T categories. The $\mathrm{pN}$ categories are based upon biopsy or surgical excision.

\section{pN - Regional Lymph Nodes}

pNX Regional lymph nodes cannot be assessed

pNO No regional lymph node metastasis

pN1 Intranodal metastasis in a single inguinal lymph node

pN2 Metastasis in multiple or bilateral inguinal lymph nodes

pN3 Metastasis in pelvic lymph node(s), unilateral or bilateral or extranodal extension of any regional lymph node metastasis

\section{pM - Distant Metastasis}

pMO No distant metastasis

pM1 Distant metastasis

\section{G - Histopathological Grading}

GX Grade of differentiation cannot be assessed

G1 Well differentiated

G2 Moderately differentiated

G3-4 Poorly differentiated/undifferentiated
The goals of penile-preserving treatments are to maintain penile/glans sensation and to maximize penile shaft length where possible. However, cosmetic and functional results should not compromise long-term oncological outcomes.

\section{Methods of Organ Preservation}

In retrospective study a variety of penile-preserving therapeutic approaches have been used for low-grade and low-stage penile carcinoma, including topical treatments (5-fluorouracil or imiquimod cream for Tis only), radiotherapy, Mohs micrographic surgery, laser ablation or excision, and conservative excision strategies [22], (Table-II). This article will focus exclusively on surgical strategies to achieve organ preservation. Nonsurgical options are beyond the scope of this review.

\section{Laser Ablation or Excision}

Penile laser surgery has been used since the 1980s. The variety of laser as carbon dioxide, argon, neodymium yttrium aluminium garnet (Nd:YAG), and potassium titanyl phosphate (KTP) lasers, the $\mathrm{CO} 2$ and $\mathrm{Nd}$ :YAG modes being the most commonly used in current practice $[22,23]$. CO2 laser has a very low penetration power (only $0.1 \mathrm{~mm}$ ) and is, therefore, unsuitable for most tumors, resulting in recurrence rates of up to $50 \%$

Table II

Organ preserving therapeutic strategies for penile carcinoma.

\begin{tabular}{ll}
\hline Nonsurgical & Surgical \\
\hline $\begin{array}{l}\text { (1) Topical treatments 5-Fluoroacil solution } \\
\text { Imiquimod cream }\end{array}$ & (1) Laser ablation or excision CO2 \\
(2) Radiotherapy & Nd:YAG, KTP \\
Plesiotherapy & (2) Mohs micrographic surgery \\
Interstitial Brachtherapy & Circumcision \\
External beam radiotherapy & (3) Conservative surgery: \\
& Glans-preserving techniques \\
& Partial glansectomy with primary \\
& closure with graft reconstruction of the glans \\
& Split-thickness skin grafts \\
& Full-thickness skin grafts \\
& Buccal mucosa graft \\
& Glans-removing techniques: Total \\
& Glansectomy with split-thickness skin \\
& grafts with distal corporectomy and \\
& reconstruction \\
\hline
\end{tabular}


[18]. Nd:YAG has a much higher penetration power of about $6 \mathrm{~mm}$ due to its rather short wavelength (10 times less than $\mathrm{CO} 2$ ), resulting in protein denaturation at such depth. Overall recurrence rates after laser ablation are also stage-dependent, averaging $7.7 \%$ for Tis tumors, and as high as $25 \%$ for $\mathrm{T} 1$ lesions [22]. Other authors have reported good outcomes after Nd:YAG laser for T1 tumors with excellent cosmetic and functional results and high satisfaction rates. Recurrences were noted in $6.9 \%$ of the patients, which is comparable to recurrence rates after partial amputation (0-8\%) [24,25].

The available data to date demonstrate that laser surgery is feasible and may achieve results comparable to those of traditional amputative surgery, particularly in highly selected patients and in conjunction with frozen-section biopsies. Additionally, it has significant anatomical, cosmetic, and functional advantages over traditional amputation. However, as the local recurrence is higher, a close surveillance is mandatory for early detection. Therefore, patient selection is extremely important.

\section{Mohs Micrographic Surgery}

Mohs micrographic surgery (MMS) refers to a surgical technique of excising accessible tumors under microscopic control [26]. The tumor is excised in layers and the undersurface of each layer is examined microscopically by systematic frozen sections in multiple sessions. This excision is continued until the undersurface of the excised tissue is negative, at which point another section of tissue is removed to ensure a clear resection margin. This sequential microscopic guidance offers increased precision and control of the negative surgical margin, while maximizing safe organ preservation. MMS is most commonly used for skin tumors but the accessibility of penile carcinomas (most commonly on the glans) makes it a suitable candidate for such a procedure. In Mohs' 50- year experience with 35 cases, the success rate was stage-dependent. A percentage of $86 \%$ of stage T1 and $82 \%$ of stage T2 cases were tumor-free compared to none of stage T3 at a follow up of 5 years.

This technique is attractive because it allows reassurance of local complete excision and preservation of local penile anatomy and function. However, because local failure rate is apparently higher (32\%) than amputation, it should be reserved to patients with penile carcinoma in situ or with small, distal, superficially invasive tumors. Further reports with this technique are necessary to allow comparison and reproducibility of outcomes in order to encourage its more widespread use. Complications may include meatal stenosis and glans disfigurement

\section{Conservative Surgery}

\section{Circumcision}

It is the most common and simple surgical procedure in the management of penile carcinoma. Most circumcision is usually done in ritual purposes. Penile cancer is usually seen in uncircumcised men. It is indicated for symptomatic treatment of painful or hemorrhagic tumors as well as for acquired phimosis secondary to preputial tumors. It is always recommended before radiotherapy as it allows better targeting, clearly define and margin free of the tumor, simultaneously preventing preputial radiotherapy-related adverse reactions. It improves local oncological surveillance. Noteworthy, circumcision alone is a sufficient primary curative treatment for low risk (low stage Tis, Ta, T1 and low-grade 1 and 2) tumor if the disease limited to the distal prepuce [27]. If the tumor is more proximal and close to the coronal sulcus, the circumcision margin will need to be extended proximally to the penile shaft to ensure adequate oncological resection, as recurrence rates may be as high as $50 \%$ [28]. Therefore, case selection is critical to reduce local recurrence rates.

\section{Glansectomy}

Treatment of small low risk lesions on the glans is debatable. It may be possible to perform a wide local excision with primary closure of the defect if the lesion is small and not too close to the urethral meatus [29]. However, closing the defect from larger lesions may lead to tilting of the glans and may affect the direction of micturition. In such cases, skin grafting may be required to cover the defect. Usually glansectomy can be done either partial or total, has recently been introduced for the local excision of distal tumors on the glans and prepuce [30, 31]. Frozen sections from the cavernosal bed and urethral stump should be carried out during the procedure to ensure negative surgical margins followed by an end-shaft urethrostomy. Glansectomy is usually combined with grafting procedures to create a new glans. Basically, there are 2 forms of glansectomy: (i) partial glansectomy, which removes the portion of the glans affected by the tumor, leaving behind remaining glanular epithelium with malignant potential, and (ii) total glansectomy, which removes all the glans tissue, thus preventing 'de novo' tumor growth.

Traditionally, the aim of amputative surgery has been based on the assumption that a $2 \mathrm{~cm}$ resection margin 
is required to achieve local oncological control [32]. However, a $2 \mathrm{~cm}$ margin resection is unnecessary and several authors have recently $[19,20,33]$ concluding in their studies that a $2 \mathrm{~cm}$ surgical margin was not only unnecessary but also overtreatment in many cases. About $80 \%$ of the penile carcinomas arise distally, which render them potential candidates for penile-preserving surgery. This type of surgery includes an extirpative component leaving in some cases a simple defect amenable to primary closure. If the defect is larger and primary closure is not possible or safe, various techniques have been suggested to cover or reconstruct the area [30, 31, 34-41]. Ubrig described a simple technique in 2001 in which an outer preputial skin flap was used to cover the glans defect if primary closure was impossible. However, the tumor should not be too deep. Pietrzak et al. have suggested the use of a fullthickness flap of penile skin or extragenital (lateral aspect of the thigh) split-thickness skin graft to reconstruct the glans associated with partial or total glans removal. In cases of invasion of tunica albuginea by distal tumors, distal corporectomy was included. In glans-preserving procedures, partial glansectomy with primary glans closure was essentially an excisional biopsy of a small distal tumor. Larger lesions necessitated partial glansectomy followed by glans reconstruction which was performed with the use of splitthickness or full-thickness grafting. In glans-removing procedures, total glansectomy was performed followed by either split-thickness skin graft reconstruction or reconstruction of cavernosal tips and grafting, if a distal corporectomy was required. In some cases, a penilelengthening procedure was added to the reconstruction to maintain as much cavernosal tissue as possible. In all forms of penile-preserving surgery, a frozen biopsy of the surgical bed is mandatory to confirm tumor clearance (negative margins). A subtotal glans excision without grafting has been described as a simple and cosmetically attractive alternative to other forms of conservative surgery for penile carcinoma [31]. This procedure involves excision of the tumor and glans between 2 incision lines leaving the urethra intact. The residual glans and urethral meatus is sutured down to the distal corpora and the penile skin is advanced to be sutured to the distal glans at the level of spatulated urethra. However, this technique should be avoided in patients with penile tumors very close to (less than 5 $\mathrm{mm}$ ) or invading the urethral meatus. Other forms of glansectomy without glans reconstruction have also been described $[30,40]$. These usually create a new urethral stoma and attach the residual urethra to the foreskin with acceptable cosmetic and functional outcomes.

Total glansectomy for penile tumors was first described by Austoni in 1996 [42]. Since that time, enormous efforts have been made in the development of more refined and appealing surgical alternatives to improve both function and cosmesis, as well as local oncological control (Table 3).

Table-III

Summary of reported complications and oncological outcomes of local treatments (2014 EUA guidelines)

\begin{tabular}{|c|c|c|c|c|}
\hline Treatment & Complications & $\begin{array}{l}\text { Local } \\
\text { recurrence }\end{array}$ & $\begin{array}{l}\text { Nodal } \\
\text { recurrence }\end{array}$ & $\begin{array}{l}\text { Cancer- } \\
\text { specific deaths }\end{array}$ \\
\hline Nd:YAG laser & none reported & $10-48 \%$ & $21 \%$ & $2-9 \%$ \\
\hline CO2-laser & $\begin{array}{l}\text { bleeding, meatal } \\
\text { stenosis (both < } 1 \% \text { ) }\end{array}$ & $14-23 \%$ & $2-4 \%$ & none reported \\
\hline Lasers(unspecified) & $\begin{array}{l}\text { bleeding ( } 8 \%) \text {, local } \\
\text { infection } 2 \%\end{array}$ & $11-26 \%$ & $2 \%$ & $2-3 \%$ \\
\hline $\begin{array}{l}\text { Moh'smicrographic } \\
\text { surgery }\end{array}$ & $\begin{array}{l}\text { local infection } 3 \% \text {, } \\
\text { meatal stenosis } 6 \%\end{array}$ & $32 \%$ & $8 \%$ & $3-4 \%$ \\
\hline Glansresurfacing & none reported & $4-6 \%$ & not reported & not reported \\
\hline Glansectomy & none reported & $8 \%$ & $9 \%$ & none reported \\
\hline Partialpenectomy & not reported & $4-13 \%$ & $14-19 \%$ & $11-27 \%$ \\
\hline Brach therapy & meatal stenosis $>40 \%$ & $10-30 \%$ & not reported & not reported \\
\hline Radiotherapy & $\begin{array}{l}\text { urethral stenosis } 20-35 \% \text {, } \\
\text { glans necrosis } 10-20 \%\end{array}$ & not reported & not reported & not reported \\
\hline
\end{tabular}


The ranges given report the lowest and highest number of occurrences reported in the different series, respectively (EUA guide line 2014).

\section{Conclusion}

Historically, amputative surgery and radical radiotherapy were the only options to treat penile carcinoma. Due to the rare nature of the disease, prospective analyses comparing organ-preserving surgeries versus conventional partial and total penile amputation are not available. Over the last two decades, several innovative techniques have been described and proposed for organpreserving surgery in penile carcinoma. These should avoid complications and maximize both cosmetic and functional outcomes, simultaneously not compromising local oncological long-term control. The most significant information is derived from large multicentre retrospective reports show relatively high local recurrence rates with organ-preserving surgery ranging from 0 to $48 \%$, with the larger studies showing rates of approximately $30 \%$. Although local recurrence is a frequent problem, it does not appear to have a significant impact on survival when recognised early, and treatment of local recurrence is in the majority of cases still organ-preserving. Diseasefree and overall survivals are generally excellent in the currently available literature. In conclusion, in highly selected cases of low-grade and low-stage penile carcinoma, organ-preserving surgery tailored to the anatomical characteristics of the lesion appears to be an excellent treatment option, preserving psychological, sexual function and upright voiding while providing satisfactory to excellent oncological outcomes.

Conflict interest: None declared.

\section{References}

1. Barnholtz-Sloan JS, Maldonado JL, Pow-sang J, Giuliano AR. Incidence trends in primary malignant penile cancer. Urol Oncol 2007; 25: 361-367.

2. Wabinga HR, Parkin DM, Wabwire-Mangen $F$ et al. Trends in cancer incidence in Kyadondo County, Uganda 1960-1997. Br J Cancer 2000; 82: 15851592.

3. Pow-Sang MR et al. Cancer of the penis. Cancer Control 2002; 9: 305-314.

4. Hakenberg OW and Wirth MP. Issues in the treatment of penile carcinoma: a short review. Urol. Int. 1999; 62: 229-233.

5. Mobilio G and Ficarra V. Genital treatment of penile carcinoma. Curr Opin Urol 2001; 11: 299-304.
6. Burgers JK et al. Penile cancer: clinical presentation, diagnosis, and staging. Urol Clin North Am 1992; 19: 247-256.

7. Jemal A et al. Cancer statistics. CA Cancer J Clin 2007; 57: 43- 66.

8. Eble $\mathrm{J}$ et al. World Health Organization classification of tumors. Pathology and genetics of tumors of urinary system and male genital organs, 2004; 93-109. Lyon: IARC press L.

9. Lewis, Young's radical operation for the cure of cancer of the penis: a report of 34 cases. The Journal of Urology 1931; vol. 26, 295.

10. McDougal WS, Kirschner FK Jr.,Edwards RH, Killion LT. Treatment of carcinoma of the penis: the case for primary lymphadenectomy. The Journal of Urology, 1986; 136(1): 38-41.

11. Horenblas S, Tinteren HV, Delemarre JFMT, et al. Squamous cell carcinoma of the penis. II. Treatment of the primary tumor. The Journal of Urology. 1992; 147(6): 1533-1538.

12. Pizzocaro G, Piva L, Bandieramonte G, Tana S. Up-to-date management of carcinoma of the penis. European Urology 1997; 32(1): 5-15.

13. Opjordsmoen S, Fossa SD. Quality of life in patients treated for penile cancer. A follow-up study. British Journal of Urology, 1994; 74(5): 652-657.

14. Pietrzak P, Corbishley C, Watkin N. Organ-sparing surgery for invasive penile cancer: early follow-up data. BJU International, 2004; 94,(9): 1253-1257.

15. Cotsadze D, Matveev B, Zak B, V. Mamaladze V. Is conservative organ-sparing treatment of penile carcinoma justified? European Urology, 2000; 38 (3): 306-312.

16. Singh AK et al. Imaging of penile neoplasms. Radiographics 2005; 25: 1629-1638.

17. Corbishley PC, Watkin N. Organ-sparing surgery for invasive penile cancer: early follow-up data. BJU International, 2004; 4,(9): 1253-1257.

18. Bissada NK, Yakout HH, Fahmy WE, et al. Multiinstitutional long-term experience with conservative surgery for invasive penile carcinoma. The Journal of Urology, 2003; 169(2): 500-502.

19. Agarwal A, Pai D, Ananthakrishnan N, Smile SR, Ratnakar C, The histological extent of the local 
spread of carcinoma of the penis and its therapeutic implications. BJU International, 2000; 85(3): 299-301.

20. Minhas S, Kayes O, Hegarty $P$, et al. What surgical resection margins are required to achieve oncological control in men with primary penile cancer? BJU International, 2005; 96(7): 1040-1043.

21. Malloy TR, Wein AJ, Carpiniello VL. Carcinoma of penis treated with neodymium YAG laser Urology, 1988; 31(1): 26-29.

22. Francisco E. Martins, Raul N. et al. OrganPreserving Surgery for Penile CarcinomaAdvances in Urology 2008; Volume (2008), 7

23. von Eschenbach AC, Johnson DE, Wishnow KI, et al. Results of laser therapy for carcinoma of the penis: organ preservation. Progress in Clinical and Biological Research, 1991; 370: 407-412.

24. van Bezooijen BPJ, Horenblas S, Meinhardt W, D. Newling WW, 2001; 5: 1670-1671.

25. Frimberger $D$, Hungerhuber $E$, Zaak $D$, et al. Penile carcinoma. Is Nd:YAG laser therapy radical enough? The Journal of Urology, 2002;168(6): 2418-2421.

26. Mohs FE, Snow SN, Larson PO. Mohs micrographic surgery for penile Tumors. The Urologic Clinics of North America, 1992; 19(2): 291304.

27. Bissada NK. Conservative extirpative treatment of cancer of the penis. The Urologic Clinics of North America, 1992; 19(2): 283-290.

28. Narayama AS, Ohney LE, Loening SA, Weimar GW, Culp DA. Carcinoma of the penis: analysis of 219 cases. Cancer. 1982; 49(10): 2185-2191.

29. Summerton DJ, Campbell A, Minhas S, Ralph DJ. Reconstructive surgery in penile trauma and cancer. Nat Clin Pract Urol 2005; 2: 391-39722.

30. Hatzichristou DG, Apostolidis A, Tzortzis V. et al. Glansectomy: an alternative surgical treatment for Buschke-Löwenstein tumors of the penis. Urology. 2001; 57(5): 966-999.

31. Brown CT, Minhas S, Ralph DJ. Conservative surgery for penile cancer: subtotal glans excision without grafting. BJU International. 2005; 96(6): 911-912.
32. Schellhammer PF, Jordan GH, Schlossberg SM. Tumors of the penis. In: Walsh PC, Retik AB, Stamey TA, Vaughn ED, editors. Campbell's Urology. 6th edition. II, chapter . 31. Philadelphia, Pa, USA: WB Saunders; 1992. 1264-1298.

33. Hoffman M, RenshwaA, Loughlin K, et al. Squamous cell carcinoma of the penis and microscopic pathologic margins. How much margin is needed for local cure? Cancer. 1999; 85: 299-300.

34. Ubrig B, Waldner M, Fallahi M, Roth S. Preputial flap for primary closure after excision of tumors on the glans penis. Urology. 2001; 58(2): 274-276.

35. Gulino G, Sasso F, Falabella R, Bassi PF. Distal urethral reconstruction of the glans for penile carcinoma: results of a novel technique at 1-year of follow-up. The Journal of Urology. 2007; 178(3): 941-944.

36. Djordjevic M, Perovic S, Martins FE. Penile disassembly for the conservative treatment of penile carcinoma. in preparation.

37. Parkash S, Ananthakrishnan N, Roy P. Refashioning of phallus stumps and phalloplasty in the treatment of carcinoma of the penis. British Journal of Surgery. 1986; 73(11): 902-905.

38. Mazza ON, Cheliz GMJ. Glanuloplasty with scrotal flap for partial penectomy. The Journal of Urology. 2001; 166(3): 887-889.

39. Djordjevic M, Perovic S, Korac G. Penile carcinoma: organ-sparing surgery. Urology. 2006; 68: 216.

40. Venkov G. Organ-sparing surgery for invasive penile cancer with use of buccal mucosal graft for resurfacing after excision of tumors on the glans penis: early follow-up data. Urology. 2003; 70(3): 288.

41. Greenberger ML, Lowe BA. Penile stump advancement as an alternative to perineal urethrostomy after penile amputation. The Journal of Urology. 1999; 161(3): 893-894.

42. Austoni E, Fenice O, Kartalas Goumas Y, et all. New trends in the surgical treatment of penile carcinoma. Archivio Italiano di Urologia, Andrologia. 1996; 68(3):163-168. (Ita)

\section{Abbreviations:}

MMS : Moh's Micrographic Surgery

MRI : Magnetic Resonance Imaging 